Jahrbuch für Geschichte Lateinamerikas

Anuario de Historia de América Latina

58 | $2021 \mid 202-233$

Rossend Rovira-Morgado
Jessica Ramírez Méndez

Universidad Autónoma de Madrid

Instituto Nacional de Antropología e Historia

El sureste de la ciudad de México, 15241542: Grupos de poder y articulación socioespacial entre españoles e indígenas


Except where otherwise noted, this article is licensed under a Creative Commons Attribution 4.0 International license (CC BY 4.0)

https://doi.org/10.15460/jbla.58.198 


\title{
El sureste de la ciudad de México, 1524-1542: Grupos de poder y articulación socioespacial entre españoles e indígenas*
}

\author{
Rossend Rovira-Morgado \\ Jessica Ramírez Méndez
}

Resumen. - El artículo da cuenta de una propuesta de organización social que se desarrolló en la zona sureste de la ciudad de México durante las dos primeras décadas posteriores a la Conquista. A partir del acercamiento a espacios concretos en esa zona, se evidencia la vinculación de ciertas personalidades de la nobleza indígena con el gobierno temporal hispano y con miembros del clero secular. En conjunto, esto permite entender que hubo otros ensayos de articulación temporal y espiritual entre los años veinte y treinta del siglo XVI, paralelos a los orquestados por los frailes doctrineros. A la vez, se cuestiona la imagen dicotómica del funcionamiento socioespacial de la ciudad respecto de la separación de las repúblicas o de la feligresía, más propia de la segunda mitad del siglo XVI.

Palabras clave: Ciudad de México, interacciones hispano-indígenas, casas del obispo, ermita de los sastres, Casas de Tapia, San Pablo, beaterio.

Abstract. - The paper deals with a project of social organization developed in the south-eastern sections of Mexico City during the two decades following the Conquest. It focuses on the collaboration of specific personalities of the indigenous nobility with both Spanish governmental institutions and secular clergymen. Empirical evidence suggests that this collaboration was opposed to the project of evangelization of the medicant friars during the 1520s and 1530s. As a result the article questions the assumption historiography has

\footnotetext{
* Los autores de este artículo agradecemos a los siguientes investigadores su asesoría bibliográfica y sus sugerencias en torno al borrador inicial: Antonio Rubial (FFyL-UNAM), Leticia Pérez Puente (IISUE-UNAM), Enrique González (IISUE-UNAM) y Caroline Cunill (École des Hautes Études en Sciences Sociales). Extendemos igualmente nuestra gratitud a los evaluadores anónimos por sus recomendaciones.
} 
established in the 16th century according to which Spanish and Indian secular and religious communities were already segregated in that early period.

Keywords: Mexico City, Spanish-Indigenous Interactions, Bishop's Houses, Hermitage of the Tailors, Casas de Tapia, San Pablo, Beaterio.

A partir del acercamiento a diversos espacios establecidos en la zona suroriental de la ciudad de México, entre los años veinte y los años cuarenta del siglo XVI, se muestran las relaciones que se tejieron entre diversas personalidades españolas e indígenas que dan cuenta de una articulación social interétnica. Acercarnos a esta propuesta nos permite visualizar otra dinámica que también tuvo cabida en la urbe durante las dos primeras décadas de la post-conquista y su incidencia en la configuración del espacio urbano. ${ }^{1}$

Como sabemos, en un primer momento prevaleció una organización social de separación étnica, apoyada en frailes, conquistadores y algunas personalidades de la nobleza indígena. Si bien en la práctica no logró imponerse del todo, sí se materializó, por ejemplo, en el trazado de la ciudad o en la configuración de las instituciones de gobierno temporal y espiritual.

Precisamente, por la preeminencia de ese acomodo, ha pasado prácticamente desapercibida por la historiografía otra tentativa que se hizo presente no sólo en el discurso, sino en algunos intentos que se pusieron en marcha en esos años. Esta otra impronta de orden social que analizaremos en este artículo llevaba implícita la convivencia de todos los cristianos -nuevos y viejos-, agrupados en un único cabildo y

\footnotetext{
${ }^{1}$ Una mirada general al tejido socioespacial de la ciudad en los años inmediatos a la conquista puede verse en Israel Hinojosa Baliño, Construcción y reconstrucción de Tenochtitlan a la Ciudad de México. Aculturación y urbanismo en el Mapa de Nüremberg y en el Mapa de Uppsala a través de un sistema de información geográfica, México: ENAH, 2009 (tesis de licenciatura en Arqueología). Jessica Ramírez Méndez, "Las nuevas órdenes religiosas en las tramas semánticoespaciales de la ciudad de México. Siglo XVI": Historia Mexicana, 62: 3 (2014), pp. 1015-1075. Barbara E. Mundy, The Death of Aztec Tenochtitlan. The Life of Mexico City, Austin: University of Texas Press, 2015, pp. 10, 11, 28, 130, 211, 213. Jessica Ramírez Méndez / Rossend Rovira Morgado, "De San Francisco el Viejo al Nuevo en la ciudad de México. Una propuesta de relectura de la primigenia traza española (1524-1525)": Estudios de Historia Novohispana, 64 (2021), pp. 161-205.
} 
administrados en lo espiritual desde las parroquias por clérigos seculares.

Para mostrar lo anterior, primero presentaremos las tentativas de gobierno temporal y espiritual -que buscaron unir a indígenas y españoles a lo largo de casi dos décadas- utilizando la categoría analítica del grupo de poder, bien conocida y con un largo recorrido en la historiografía relativa a las sociedades urbanas de Antiguo Régimen.? Ya, en un segundo momento, nos acercaremos al análisis específico de la zona sureste a partir de los emplazamientos que, detectamos, dan cuenta de los intentos de su puesta en práctica en los que, cabe decir, destaca un reducido, pero altamente activo, clero secular. Ello supuso un ensayo de articulación social distinto al de los frailes mendicantes y sus adeptos, desarrollado, desde 1524, sobre todo en la zona poniente de la urbe, y tendiente a la separación étnica. ${ }^{3}$

Como tendremos ocasión de argumentar, la tentativa expuesta en este trabajo no logró asentarse en esos años, evidenciando su ocaso entre la segunda mitad de los años 1530 y la primera de los 1540. En efecto, la emisión de la renombrada bula Sublimis Deus (1537) -que disponía la libertad jurídica entre los indígenas y su capacidad autónoma para recibir la doctrina cristiana-, la promulgación de las primeras ordenanzas para la institucionalización progresiva de los cabildos nativos (ca. 1537-1539), ${ }^{4}$ y la recepción de las Leyes Nuevas

2 José María Imízcoz Beunza, "Comunidad, red social y élites. Un análisis de la vertebración social en el Antiguo Régimen”: José María Imízcoz Beunza (dir.), Elites, poder y red social, Bilbao: Euskal Herriko Unibersitatea, 1996, pp. 13-50. Siro Villas Tinoco, "Poder y poderes en la ciudad del Antiguo Régimen": Baetica. Estudios de Arte, Geografía e Historia, 21 (1999), pp. 355-382. Cristopher R. Friedrichs, Urban Politics in Early Modern Europe, Londres / Nueva York: Routledge, 2000, pp. 7-10. Karen Melvin, Building Colonial Cities of God. Mendicant Orders and Urban Culture in New Spain, Stanford: Stanford University Press, 2012, pp. 19-20.

${ }^{3}$ Jessica Ramírez Méndez, “¿Ubicaciones fortuitas? La concepción y Santa Clara en la Ciudad de México. 1540-1585": Revista de Indias, 272 (2018), pp. 49-78. Jonathan G. Truitt, Sustaining the Divine in Mexico Tenochtitlan. Nahuas and Catholicism. 1524-1700, Norman: University of Oklahoma Press, 2018.

4 "Traslado de ciertas Ordenanzas fechas por el Abdiencia Real insertas en una provisión sellada con el sello real", 10 de junio de 1539, ciudad de México: Alberto María Carreño (ed.), Un desconocido cedulario del siglo XVI, México: Ediciones Victoria, 1944, pp. 130-135. 
(1542) en el distrito de la Real Audiencia de México minaron tales pretensiones de adhesión interétnica.

No obstante, acercarnos a esta iniciativa aporta elementos para entender de manera más dinámica la articulación social y espacial de México-Tenochtitlan en ese momento; de hecho, en ese tenor, da cuenta de por qué los experimentos para implementarla tuvieron cabida en la zona sureste. En un espectro más general, ayuda a entender los cambios y las continuidades en el gobierno temporal y espiritual, así como las alianzas y los conflictos derivados de ello que se dieron en la segunda mitad del siglo XVI. (Figura 1)

Figura 1: Ubicación, en la ciudad de México del siglo XVI, de los sitios más representativos discutidos a lo largo de este estudio ${ }^{5}$

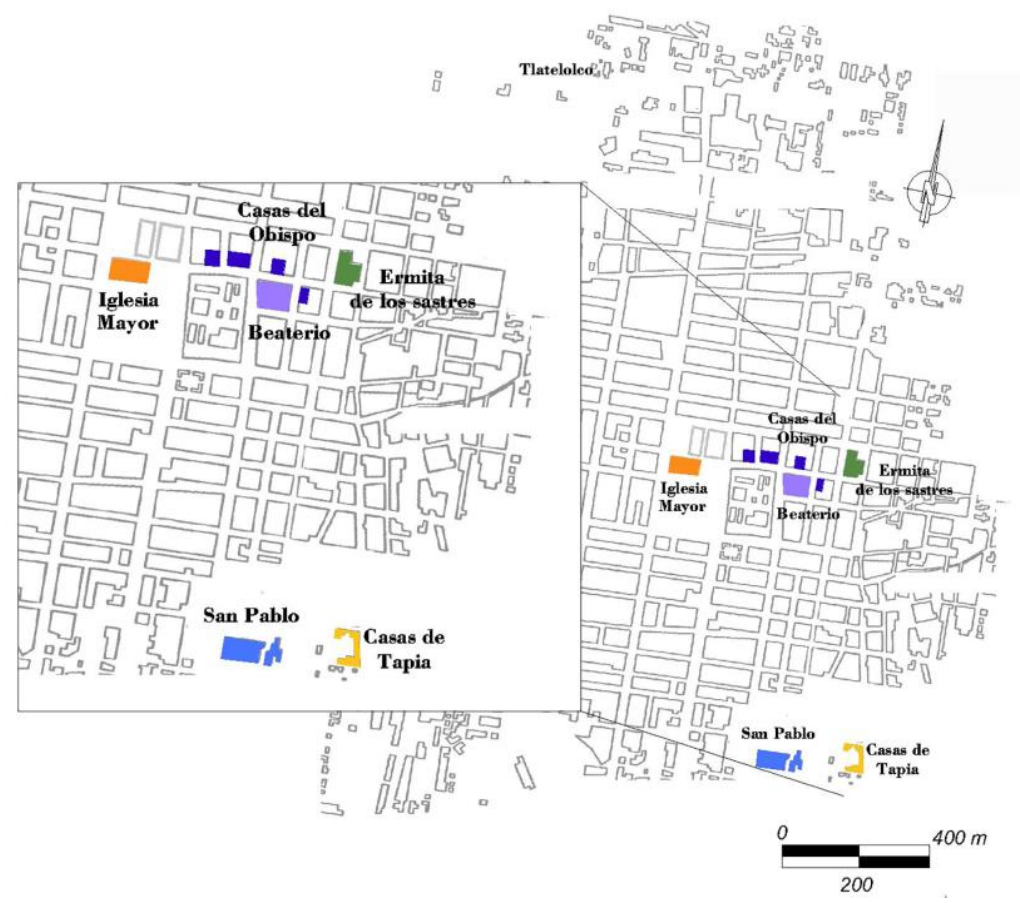

5 Diseño de los autores. 


\section{Experimentación de proyectos de gobierno espiritual y temporal}

En 1524 comenzó formalmente el establecimiento de los célebres doce franciscanos en la ciudad y, dos años después, el de los dominicos. Con ello, a lo largo de los años veinte, se dieron los primeros pasos de la evangelización indígena al unísono de los de la organización general del otrora corazón mexica. Ya en 1530 se creó la diócesis de México, aunque dos años antes había llegado fray Juan de Zumárraga como obispo presentado. ${ }^{6}$ A partir de ese momento, se orquestaron los primeros ensayos en torno al funcionamiento episcopal en la urbe.

De hecho, aunque se le ha prestado más atención a la organización de la sociedad en torno al clero regular, mediante las noticias contenidas en la real cédula que Carlos V giró el 2 de agosto de 1533 a la Segunda Audiencia (1530-1535), sabemos que Isabel de Portugal, como regente, había remitido ya unos capítulos previos, hacia 1530, en los que conminaba a la construcción de iglesias parroquiales. Al respecto, la regente ordenaba que se incrementara el gravamen tributario a los indios y que se destinara una cuarta parte de ello para satisfacer el pago de los salarios de los clérigos a cargo de las nuevas parroquias que se fueran instaurando. ${ }^{7}$

En efecto, en el verano de ese año se registró que, de los cinco capellanes catedralicios, había dos que servían "dos iglesias de parroquias en esta dicha cibdad, en las cuales dicen misa e baptizan a los naturales de esta tierra e se les predica la palabra de Dios cada domingo". ${ }^{8}$ La identificación de esas primitivas parroquias se dilucida en fuentes del año 1532. El 31 de enero se expidió una real cédula para

\footnotetext{
${ }^{6}$ Fray Juan de Zumárraga viajó a la Península Ibérica a finales de 1532 para recibir la consagración (1533).

7 Real cédula de Carlos V a la Segunda Audiencia, "La quarta para yglesias que se hazen”, 2 de agosto de 1533, Monzón. Vasco de Puga, Prouisiones, cedulas, instrucciones de Su Magestad, ordenanças de difuntos y audiencia para la buen expedicion de los negocios y administracion de justicia y gouernacion de esta Nueua España y, para el buen tratamiento y conseruacion de los indios desde el año de 1525 hasta el presente del 63, ciudad de México: 1563, folios 88r-88v.

8 Diego Velázquez, notario público apostólico, "Al Obispo, que dé congrua sustentación a su Cabildo, e informe al respecto", 14 de julio de 1530, ciudad de México: Carreño, Un desconocido, p. 63. Esos cinco curas capellanes eran Juan Díaz, Hernán Martín Salvador, Antón Comitre, Rodrigo de Torres y Diego Velázquez.
} 
que el presidente Sebastián Ramírez de Fuenleal beneficiase al clérigo Juan Díaz con el curato de Tlatelolco. ${ }^{9}$ Y, en mayo, se dejó constancia de que esas parroquias eran, precisamente, la de San Pablo y la de Santiago [Tlatelolco]-emplazamientos eminentemente indígenas-, a cuyo cargo quedaron, al final, los curas capellanes Alejo de Villanueva y Rodrigo de Torres, respectivamente. ${ }^{10}$

Al año siguiente, Ramírez de Fuenleal expresaba su preocupación por la institución del distrito parroquial de la Iglesia Mayor. ${ }^{11}$ Finalmente, en 1534, la Corona dictó la conocida provisión dirigida al presidente de la Segunda Audiencia y a Zumárraga, a fin de que se valorase la idoneidad de continuar creando estas parroquias urbanas tanto en los templos existentes como en los que estuvieran por edificar. ${ }^{12}$

${ }_{9}^{9}$ Real cédula de Isabel de Portugal, "J ${ }^{0}$. Diez clerigo // present. ${ }^{0}$ al ben. ${ }^{0}$ de sattiago del tatelulco", 31 de enero de 1532, Medina del Campo. Folio 168v. Archivo General de Indias [en adelante AGI], México, 1088, L.1bis. Recordamos que la ermita de Santiago Tlatelolco se erigió en 1526/1527. Funcionó como "ayuda" de San José de los Naturales hasta que, en 1530, se convirtió en iglesia parroquial. En 1536 se fundó en sus adyacencias el Colegio de Santa Cruz y, en 1543, quedó establecido formalmente un convento franciscano.

${ }^{10}$ Juan de Zumárraga, "Erección provisional de la Catedral", 27 de mayo de 1532, ciudad de México: Carreño, Un desconocido, p. 77. Alejo de Villanueva había estado relacionado con la diócesis de Santo Domingo y pasó a Nueva España hacia 1531, tal vez acompañando a Ramírez de Fuenleal. En 1532, fue recomendado ante Zumárraga para que recibiese algún beneficio curado; posiblemente, San Pablo de México. Real cédula de Carlos V, "Alexo de Vạnueva // present. ${ }^{0}$ [...] de la yglesia della spañola", 21 de agosto de 1528, Madrid. Folios 329r-329v. AGI, Indiferente General, 421, L.13. Real cédula de Isabel de Portugal, "Alexo de Villannueba // c.rigo", 25 de abril de 1532, Medina del Campo. Folio 67v. AGI, México, 1088, L.2.

11 Sebastián Ramírez de Fuenleal, "Carta”, 1 de marzo de 1533, ciudad de México. Folio 1r. AGI, 68, R.3, N.6.

12 Real cédula de Carlos V, "Al presidente de la Nueva España e Obispo de México, que provean lo que vieren que era más conveniente [...]”, 20 de febrero de 1534, Toledo: Carreño, Un desconocido, pp. 89-90. Para una minuciosa discusión crítica en torno a la cronología de erecciones parroquiales en la ciudad, véase Leticia Pérez Puente / Óscar Reyes Ruiz, "En razón del bien común. Las parroquias y el ayuntamiento de la ciudad de México, siglos XVI y XVII": Francisco Javier Cervantes Bello / María del Pilar Martínez López-Cano (coords.), La Iglesia en la construcción de los espacios urbanos. Siglos XVI al XVIII, México: IIHUNAM/BUAP, 2019, pp. 129-148. 
Teniendo en cuenta, pues, que los primeros clérigos que administraron San Pablo y Santiago Tlatelolco fueron capellanes que cobraban emolumentos a los feligreses a los que prestaban servicios y que, a la par de ellos había presencia franciscana, sería pertinente entender el funcionamiento de estos curatos $y$, en general, el del gobierno espiritual en esos años, a partir de vínculos personales y no territoriales. Así, no sorprende tampoco que el ayuntamiento incentivara la cesión de solares a particulares y corporaciones españolas para que levantaran nuevas ermitas a extramuros de la "traza" en la que debían desenvolverse. Tal fue el caso de las de San Antonio Abad (1530), ${ }^{13}$ y de San Cosme, San Damián y San Amaro (1526) ${ }^{14}$-ambas ubicadas en el sur y el oriente de la ciudad-, así como una ermita de San Lázaro (1532-1533), localizada en el suroeste urbano. ${ }^{15}$

Estrechamente conectada a estos asuntos eclesiásticos en los que la frontera étnica se desdibujaba, en 1530 la Corona apoyó la iniciativa de conjuntar las jurisdicciones civiles española e indígena de la ciudad de México en un único ayuntamiento y cabildo. ${ }^{16}$ En efecto, en las instrucciones que la regente expidió a la Audiencia novohispana se pedía que

"para que los indios naturales de aquella provincia comenzasen a entender nuestra manera de vivir, así en su gobernación como la policía y cosas de la república, sería provechoso que hubiese personas de ellos que, juntamente con los regidores españoles que están proveídos, dos entrasen en el regimiento y tuviesen voto en él [...]; por ende, después que hayáis entendido y platicado las cosas de aquella tierra, informándoos de las personas más calificadas de la

1319 de enero de 1530, Actas del Cabildo de la Ciudad de México [en adelante ACCM]: Ignacio Bejarano (ed.), México: Municipio Libre, 1889, 23 vols., libro 2, p. 30 .

149 de enero de 1526, libro 1, ACCM, p. 71.

15 Cfr. 31 de enero de 1533, libro 3, ACCM, p. 17.

16 Esta idea afloró de nuevo durante las décadas de 1550 y 1560. No obstante, a lo largo del siglo XVI, se acabaron materializando dos corporaciones socio-jurídicas en la ciudad de México: la república de españoles y la república de indios, representada en los cabildos de San Juan Tenochtitlan y Santiago Tlatelolco. Rossend Rovira Morgado, "'Se ha de suplicar que los regimientos de esta ciudad sean veinticuatrías'. El cabildo de Granada como propuesta institucional interétnica en la temprana república de la ciudad de México": Estudios de Historia Novohispana, 55 (2016), pp. 80-98. 
ciudad de México y que parezca que tienen más habilidad e inclinación a la cosa pública, llamaréis dos ellos por regidores, y otro por alguacil, y de nuestra parte les hablaréis dándoles a entender esta instrucción nuestra; y, llenos sus nombres en ellas, dadles los títulos y hacedles recibir en el ayuntamiento, y hablaréis a los alcaldes y regidores [españoles] que los traten muy bien [...]".17

Se trataba de una colaboración interétnica -sin concebirla en igualdad de circunstancias o número de participantes- como parte de las tentativas de gobierno y de organización hispana. En ese sentido, resulta altamente probable que los procuradores españoles de la ciudad de México y la Corona habrían estado interesados en concretar entonces esa hibridación institucional corporativa aprovechando el delicado ínterin de 1529/1530-1532, en el cual la gobernación indígena quedó acéfala tras el repentino fallecimiento del cacique Andrés de Tapia Motelchiuhtzin (ca. 1530). La Segunda Audiencia no estuvo en disposición de ratificar a un nuevo mandatario tenochca sino hasta 1532. Este fue Pablo Xochiquentzin (1532-1536). ${ }^{18}$

Así pues, durante el bienio de 1530-1532, se dieron los primeros pasos para ir atrayendo a ciertos principales mexicas hacia los intereses del órgano municipal español. Hasta donde hemos podido recabar información, no se tiene constancia documental de las pesquisas efectuadas al respecto por la Segunda Audiencia, o de la matriculación de posibles candidatos en dos regidurías y un alguacilazgo indígenas en el seno del ayuntamiento español durante este escueto interludio de dos años. Y aún menos, con la instalación de Xochiquentzin en 1532, puesto que Ramírez de Fuenleal pretextó al año siguiente ante la Corona no realizar tales nombramientos, aduciendo que, como los naturales "entre sí tienen mejor orden de elegir oficiales, no conviene que sepan la mala

${ }^{17}$ Real cédula de Isabel de Portugal con instrucciones a la Audiencia de México, “Que presidente y oidores envíen regidores indios, que entren en cabildo", 17 de julio de 1530, Madrid. Puga, Prouisiones, folio 40r [año MDXXXI].

18 Paule Obadia-Baudesson (ed.), Historia de los mexicanos por sus pinturas, París: Association Oxomoco et Cipactonal, 1988, cap. XX. En este contexto de vinculación interétnica sería igualmente necesario insertar el ofrecimiento que, hacia 1532, se presentó a doña Isabel de Moctezuma, pues algunos principales "no hallaban otro legítimo Señor sino á ella y á su hijo que se dice [Juan Gallego Andrade], hijo de Pedro Gallego, ya difunto, marido que fué de la dicha Doña Isabel, é que lo querían nombrar é dar noticia al Presidente é Oidores". "Origen de los mexicanos": Joaquín García Icazbalceta (ed.), Nueva Colección de Documentos para la Historia de México, México: Editorial Chávez Hayhoe, 1941 (1532), p. 305. 
que entre españoles hay. Ahora no conviene [que estos dos regidores nativos] se provean".19 Aun así, ciertos datos apuntan hacia la posibilidad de que los magistrados españoles habrían tanteado previamente a ciertas personalidades nahuas de Tenochtitlan y Tlatelolco -acaso en las aludidas parroquias de San Pablo y Santiagopara esta colaboración concejil de tipo interétnico.

De hecho, un sugerente personaje en Tenochtitlan fue Hernando de Tapia, hijo de Motelchiuhtzin, y residente, precisamente, en San Pablo. Antes de finales de 1532 -cuando embarcó rumbo a la Península Ibérica-, Tapia figuró como gestor de las finanzas públicas indígenas de la ciudad de México. Los oidores de la Segunda Audiencia lo dibujaron como un principal aficionado a los círculos españoles, a quien "siempre le hacemos buen tratamiento y muestra estar contento". ${ }^{20}$ Asimismo, las actas de cabildo lo retrataron como el encargado de movilizar la mano de obra indígena en el cultivo de los campos. ${ }^{21} \mathrm{Y}$ figuró como litisconsorte de los señores y principales de Tlatelolco en el conflicto judicial contra la encomienda de Ecatepec. ${ }^{22}$

Pero, durante ese bienio de 1530-1532, para Hernando de Tapia pesó mucho más la voluntad de conseguir heredades y rentas a perpetuidad que la "habilidad e inclinación a la cosa pública" de la ciudad de México. Los altos jueces de la Audiencia admiraban su destreza, pero le achacaban que "publica que ha de ir a [Castilla a ver] a Vuestra Majestad a que le haga merced de un pueblo en que tenga de comer, por los servicios de su padre". ${ }^{23}$

Finalmente, Hernando de Tapia fue trasladado a España en los últimos meses de 1532. Recordando ese viaje años más tarde, en su testamento de 1555, razonó que "[...] yo fui a los reinos de Castilla puede haber veinte cinco años poco más o menos, y yo y otros principales de

19 Sebastián Ramírez de Fuenleal, "Carta a la Emperatriz", 15 de mayo de 1533, ciudad México: Francisco del Paso y Troncoso / Silvio Zavala (eds.), Epistolario de la Nueva España. Volumen XV, México: Porrúa, 1942, pp. 164-165.

20 "Carta de la Abdyencia de Mexico a Su Magestad sobre varios asuntos de Gobierno", 14 de agosto de 1531, México: CODOIN, tomo XLI, Madrid: Imprenta de Manuel G. Hernández, 1884, p. 111 [en adelante "Carta de la Abdyencia"].

218 de marzo de 1531, libro 2, ACCM, p. 94.

22 Amos Megged, “Cuauhtémoc's Heirs”: Estudios de Cultura Náhuatl, 37 (2007), p. 353.

23 "Carta de la Abdyencia", p. 111. 
esta ciudad de México íbamos a negociar cosas tocantes a esta ciudad de México". ${ }^{24}$

Por otra parte, en el caso de Tlatelolco, aunque no dispongamos de evidencias concluyentes al respecto, tal vez cabría interrogarse sobre el papel que desempeñó su cacique y gobernador -don Juan Quahuicónoc (1530/31-1537)- en estas experimentaciones gubernativas y diocesanas.

Y es que cabe recordar que, con la llegada de la Segunda Audiencia, algunos oidores utilizaron la asesoría de jurisconsultos indígenas en los pleitos de los naturales. En efecto, Vasco de Quiroga y Francisco de Ceinos solían reunirse con ancianos de México y, precisamente, de Tlatelolco. ${ }^{25}$ Tales dinámicas coincidieron con varios procesos en los que Quahuicónoc y otros principales se vieron envueltos contra los titulares de las encomiendas de Ecatepec (Leonor de Moctezuma, Cristóbal Valderrama) y Xaltocan (Gil González de Benavides), lugares y personalidades vinculados a la esfera cortesiana y franciscana.

De hecho, como parte del citado pleito con Ecatepec, se hizo evidente el desacuerdo ante el uso de la mano de obra indígena procedente de las aldeas de Coatitlan y Acalhuacan para la edificación del convento de San Francisco, para la eventual fuerza de trabajo y materiales que solicitaran los religiosos seráficos, y para el servicio de la encomendera y de su primer y segundo esposo (Juan Páez y Cristóbal de Valderrama, respectivamente). A inicios de los años 1530, Quahuicónoc y otros principales de Tlatelolco y Tenochtitlan, cansados en apariencia de tal situación, convocaron a los mandatarios de esas estancias en el domicilio del oidor Juan de Salmerón, quien resolvió que dichos

24 Testamento de Hernando de Tapia, 26 de marzo de 1555, ciudad de México. Folios 77v-94v: folio 88r. Archivo General de la Nación de México [en adelante AGN], Tierras, vol. 37, exp. 2. Rossend Rovira Morgado, "Lengua, identidad y residencialidad indígenas en la Ciudad de México de la primera centuria virreinal. El caso del nahuatlato Hernando de Tapia": Caroline Cunill / Luis Miguel Glave Testino (coords.), Las lenguas indígenas en los tribunales de América Latina. Intérpretes, mediación y justicia (siglos XVI-XXI), Bogotá: ICANH, 2019, p. 24.

25 AGI, Justicia, leg. 232, n. 1. Ethelia Ruiz Medrano, Mexico's Indigenous Communities. Their Lands and Histories. 1500 to 2010, Boulder: University Press of Colorado, 2010, p. 24. Ethelia Ruiz Medrano, Gobierno y sociedad en Nueva España. Segunda Audiencia y Antonio de Mendoza, México: Gobierno del Estado de México-COLMICH, 1991, pp. 44-46, 97. 
"sujetos" de Ecatepec dejaran de acudir a esa cabecera y sirvieran con exclusividad a las autoridades indígenas de México. ${ }^{26}$

Como se observa para Tlatelolco, los datos expuestos nos permiten plantear sugestivos enlaces entre la Segunda Audiencia con varios agentes indígenas y, especialmente, con Quahuicónoc. Asimismo, se entrevé el descontento de algunos principales con los franciscanos y, con ello, su probable predilección por los clérigos seculares presentes en la parroquia de Santiago. ${ }^{27}$ Sin ningún ápice de sospecha, la familiaridad de Quahuicónoc con los agentes diocesanos se hizo patente en la información aportada por Ana de Rebolledo, testigo española que

“oyó decir a Diego Díaz y a Luis Méndez, clérigos, que ellos le habían visto hacer [al gobernador tlatelolca] un rosario de cuentas grandes de oro, y preguntado para quién eran él respondió que para doña Leonor, mujer del [oidor] Ceynos".28

En conjunto resulta evidente que, paralelo al proyecto que implicaba la separación entre indígenas y españoles, estaba presente el de otros grupos de poder que impulsaban un gobierno espiritual y temporal interétnico, especialmente a inicios de los años treinta del siglo XVI. Ante el casi monopolio del área poniente por los franciscanos, ${ }^{29}$

26 AGI, Justicia, vol. 124, n. 5. AGI, Justicia, vol. 159, n. 5. Margarita VargasBetancourt, Land, Water, and Government. Tlatelolco in the Sixteenth and Early Seventeenth Centuries, Nueva Orleans: Tulane University, 2015 (tesis doctoral en Historia), pp. 112-113, 116-117.

27 En el Nican mopohua -relatando la mariofanía en el Tepeyac, así como las idas y venidas de Juan Diego a la ciudad de México en diciembre de 1531- se retrata a Tlatelolco como el lugar de la prédica de la teóyotl ("cosas divinas") con los toteopixcahuan ("nuestros sacerdotes"). El obispo Zumárraga es reportado como teopixcatlatoani ("gobernante de los sacerdotes"). Teopixqui aparece traducido indistintamente como "ecclesiastico, clerigo, o religioso". Aunque cabe suponer que se trataba de agentes seculares, este aspecto léxico oscurece la identificación contundente del tipo de clero que estuvo a cargo de Tlatelolco en estos años. Miguel León-Portilla, Tonantzin Guadalupe. Pensamiento náhuatl y mensaje cristiano en el "Nican mopohua", México: El Colegio Nacional-FCE, 2000, pp. 94-95, 100-101, 138-139. Alonso de Molina, Vocabulario en lengua castellana y mexicana, México: Casa de Antonio Espinola, 1571, 101r [nah.].

${ }_{28}$ AGI, Justicia, leg. 232, n. 1. Armando Mauricio Escobar Olmedo, Don Vasco, el Oidor. Juicio de residencia que Francisco de Loaysa hizo a los oidores Vasco de Quiroga, Juan de Salmerón, Francisco de Ceynos y Alonso de Maldonado. México, año de 1536, Ávila: Institución Gran Duque de Alba, 2016, p. 232.

${ }^{29}$ Ramírez Méndez / Rovira Morgado, “De San Francisco”, pp. 161-205. 
veremos que estas tentativas tuvieron cabida en la zona suroriente donde convivieron de manera asidua personalidades del gobierno indígena y miembros del clero secular.

\section{Ensayos de interacción hispano-nahua en el sureste de la ciudad}

A tenor de las biografías esbozadas, vale la pena detenerse en la zona sureste donde encontramos de manera más evidente la cristalización de tales grupos de poder en el arreglo socioespacial. Y es que, en las primeras décadas de la post-conquista, la ciudad miraba hacia el poniente, ${ }^{30}$ lo que condicionó el desarrollo físico y social del sureste. Así, a partir del acercamiento a las dinámicas de espacios concretos en los años veinte y treinta del siglo XVI, veremos esos experimentos corporativos y gubernativos espirituales y temporales que entretejían a indígenas y españoles en la zona suroriente, tentativa interétnica en la que participó activamente el clero secular. Puntualmente, analizaremos el área de las casas del obispo, la ermita de los sastres, las Casas de Tapia, San Pablo y el beaterio, mismos que presentamos en el fragmento del Mapa de Uppsala (ca. 1537-1550) (Figura 2). Aunque no nos detenemos en ello, la historiografía ya ha señalado la relación de este mapa con la población indígena y con los franciscanos al considerar que fue hecho en el Colegio de Santa Cruz Tlatelolco. Bajo unas rigurosas directrices seráficas en su confección, esta pictografía tenía que ser enseñada en la Corte, de ahí que quedaron vertidos en ella elementos que permiten diversas lecturas, tal y como advertiremos. ${ }^{31}$

30 Esto por la propia orientación heredada del Templo Mayor, pero también por cuestiones de seguridad y firmeza del suelo, lo que ocasionó su rápida redistribución solariega, poblamiento y la ubicación de los primeros poderes en esa zona. Ramírez Méndez, "Las nuevas”, pp. 1015-1075.

${ }^{31}$ Susan Toby Evans, "The Aztec Palace under the Spanish Rule. Disks Motifs in the Mapa de México de 1550 (Uppsala Mapa or Mapa de Santa Cruz)": Susan Kepecs / Rani T. Alexander (eds.), The Postclassic to Spanish-Era Transition in Mesoamerica. Archaeological Perspectives, Albuquerque: University of New Mexico Press, 2005, pp. 14-33. Nino Vallen, "Healing Power. Land-Surveying Politics and the Archive of Mendoza's America (1535-1552)": Romy Kohler / Anne Ebert (eds.), Las agencias de lo indígena en la larga era de globalización. Microperspectivas de su producción y representación desde la época colonial temprana hasta el presente, Berlín: Gebrüder Mann Verlag, 2015. Miguel León- 


\section{Figura 2: Sección sureste de la ciudad de México en el Mapa de Uppsala (ca. 1537-1550) ${ }^{32}$}

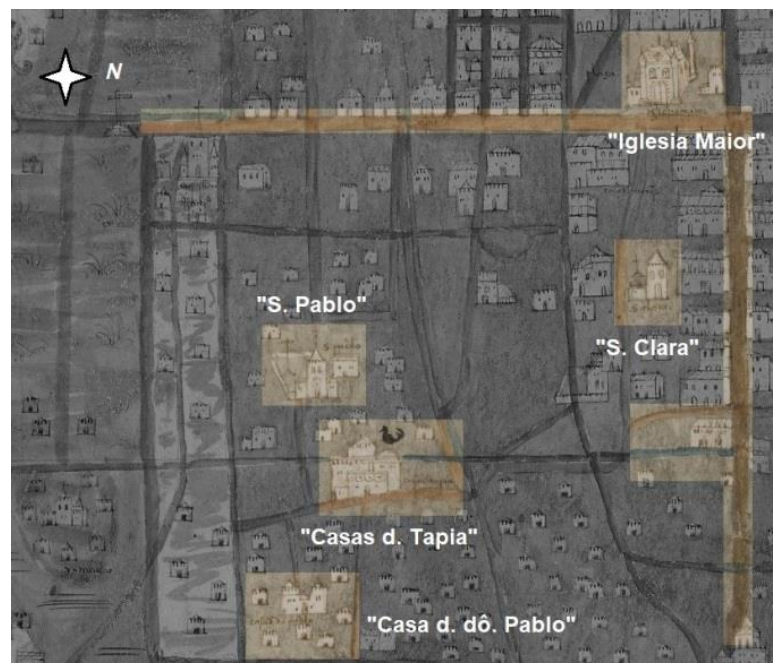

\section{El área de las casas del obispo}

En 1525 ya había comenzado la erección de la Iglesia Mayor. ${ }^{33}$ El cura encargado era Pedro de Villagrán, ${ }^{34}$ que vivía cerca del ya señalado padre Luis Méndez, ${ }^{35}$ sobre la calle que iba a las Atarazanas (República de Guatemala). ${ }^{36}$ Resulta sugerente que los inicios de su precaria construcción -independiente de las Casas Viejas de Hernán Cortés y alejada de los franciscanos- y las dotaciones solariegas en las que se menciona a esos miembros del clero secular se dieron en el periodo de gobierno de Gonzalo de Salazar y Juan Peralmíndez. Así, aparentemente,

Portilla / Carmen Aguilera, Mapa de México Tenochtitlan y sus contornos hacia 1550, México: Instituto de Investigaciones Históricas- UNAM, Ediciones Era, 2016.

32 Se enfatizan los espacios discutidos con sus respectivas glosas. El espacio sin glosar refiere a la ermita de los sastres, antecedente de la Santísima Trinidad.

3323 de noviembre de 1525, libro I, ACCM, p. 62.

${ }^{34} 28$ de noviembre de 1525, libro I, ACCM, p. 62.

3526 de septiembre de 1525, libro I, ACCM, p. 57.

${ }^{36} 12$ de enero de 1526, libro I, ACCM, p. 72. En paréntesis hacemos alusión al nombre que lleva la calle actualmente la primera vez que se le menciona. 
el primer impulso de tal clerecía se dio de la mano de la facción contraria a Cortés, al otro lado de la plaza. ${ }^{37}$

En 1530 fray Juan de Zumárraga adquirió solares para construir su vivienda provisional en la calle de Martín López (Moneda), ${ }^{38}$ en parte de lo que había sido el templo de Tezcatlipoca, al sureste del recinto sagrado del Templo Mayor. ${ }^{39}$ Comenzaron las adecuaciones de la vivienda episcopal, fungiendo como mayordomo de la Iglesia Mayor el comentado conquistador y después encomendero Cristóbal de Valderrama, ${ }^{40}$ lo que podría revelar la inicial proximidad de fray Juan con la facción franciscana. Ahí vivía ya el electo en julio de $1531{ }^{41}$

En ese mismo año, Zumárraga adquirió otras dos casas; una para la cárcel eclesiástica en su primera ubicación (Academia casi esquina con Moneda) ${ }^{42}$ y la otra para que en ella se fabricaran campanas (licenciado Verdad esquina con Moneda). ${ }^{43}$ La primera fue comprada al deán presentado Manuel Flores y la segunda, a Diego de Soria. ${ }^{44}$ Además, junto a la de la cárcel, el obispo adquirió otra casa, muy probablemente

${ }^{37}$ Cabe recordar que las misas se daban en las Casas Viejas de Cortés y que, en su juicio de residencia, se le acusó de no haber hecho Iglesia Mayor. José Luis Martínez, Documentos cortesianos, tomo IV, México: Facultad de Filosofía y Letras-UNAM, Fondo de Cultura Económica, pp. 37, 131.

38 "Escritura de venta de las casas Arzobispales, otorgada por Hernán Medel", 21 de marzo de 1530, México: Joaquín García Icazbalceta (ed.), Don Fray Juan de Zumárraga. Primer obispo y arzobispo de México, tomo II, México: Porrúa, 1947 (1881), pp. 256-261.

${ }^{39}$ Fray Diego Durán, Historia de las Indias de Nueva España e islas de la Tierra Firme, tomo II, México: Imprenta de Ignacio Escalante, 1880, cap. LXXXIII, p. 107.

40 "Partidas del libro de cuentas del Sr. Zumárraga, anotaciones propias", 10 de abril de 1530, México: García, Don Fray, tomo II, p. 310.

${ }^{41} 14$ de julio de 1531, libro II, ACCM, p. 117. Ver Carlos de Sigüenza y Góngora, Piedad heroica de don Fernando Cortés marqués del Valle, México: Antigua imprenta de Murguía, 1928, p. 53.

${ }^{42}$ La cárcel fue mudada en torno a 1539-1540, pues, de hecho, donde estaba se convirtió en el Hospital de Bubas. "Carta del obispo de México, Fr. Juan de Zumárraga, a su sobrino Sancho García de Larraval, en Durango", 23 de agosto de 1539, México: García, Don Fray, tomo III, p. 185.

43 "Cédula del Emperador a la Segunda Audiencia", 2 de agosto de 1533, Monzón: García, Don Fray, tomo III, p. 74.

44 "La relación que dio Francisco de Herrera, el viejo, acerca de las escrituras de las Casas Arzobispales para la Catedral”, 27 de marzo de 1531, México: García, Don Fray, tomo II, pp. 261-262. 
en la que luego se educaron a las mujeres tenochcas, a la que se sumó una más que albergó a las beatas que se encargaron de su educación, como veremos más adelante. ${ }^{45}$ Asimismo, se hizo de cuatro casas que se describen con tiendas (Moneda). Una de ellas había pertenecido en 1536 al padre Francisco de Alegría. ${ }^{46}$ Ya más tardíamente, en torno a finales de 1539 o principios de los cuarenta, Zumárraga adquirió las casas a las que mudó la cárcel prácticamente al lado de su residencia. ${ }^{47}$ Como se ve, sobre Martín López habitaba el cura Francisco de Alegría, el deán presentado Manuel Flores y, más tarde, en 1536, el canónigo Miguel de Palomares. ${ }^{48}$ Además, a espaldas de la cárcel vivía el clérigo Francisco Martínez $\mathrm{y}^{49}$ también, más al sur, estaba presente en San Pablo el capellán Alejo de Villanueva. ${ }^{50}$

En conjunto, el acercamiento a esta decena de casas adquiridas por el electo puede apuntar que emprendió la tarea de materializar la jerarquía eclesiástica en una zona con presencia secular que le antecedía, intentando consolidarla con él a la cabeza. Desde su llegada, Zumárraga probablemente entendió que el oriente era el espacio desde el que podía extender su influencia y, ${ }^{51}$ más aún, porque hacia allí se había desplazado el gobierno indígena, como examinaremos. Es más, dada su estrecha relación para ese momento con sus hermanos de orden y su estadía con ellos a su llegada, en un primer momento pudo ser una iniciativa conjunta para incidir en esa área. No obstante, con el propio fortalecimiento episcopal y la distancia que como consecuencia

45 "Carta de la Abdyencia", p. 118-121.

${ }^{46}$ AGN, Archivo Histórico de Hacienda, leg. 2326, folios 163-164. Guillermo Porras Muñoz, Personas y lugares de la ciudad de México. Siglo XVI, México: IIH-UNAM, 1988, p. 146.

47 Alberto María Carreño (ed.), Don fray Juan de Zumárraga, teólogo y editor, humanista e inquisidor, México: Editorial Jus, 1950, p. 107.

4820 de octubre de 1536, libro IV, ACCM, p. 44.

497 de marzo de 1536, libro IV, ACCM, p. 11. El 10 de noviembre de ese mismo año se le dotó de otro solar en la misma zona. Libro IV, ACCM, p. 50.

${ }^{50}$ Para 1532 había escasos clérigos seculares. Estaban el presentado deán Manuel Flores, los presentados canónigos Alonso López, Gaspar López, Pedro de Morales, Juan Bravo, Juan Juárez y Diego Vázquez; como curas Francisco Martino, Juan Pedro Materano y Alonso de Monsalve. Juan de Zumárraga, “Erección provisional de la Catedral”, 27 de mayo de 1532, México: Carreño, Un desconocido, pp. 74-77.

${ }^{51}$ Ramírez Méndez, “Las nuevas”, pp. 1015-1075. 
se generó con los frailes, esa zona terminó por consolidarse como un reducto principalmente secular.

\section{La ermita de los sastres}

Por su celeridad en aparecer, un segundo espacio a tener en consideración fue la primitiva ermita de la cofradía y hermandad de los alfayates, que actuó como antecedente de la iglesia de la Santísima Trinidad.

En efecto, el 9 de enero de 1526, Francisco de Olmos y Juan del Castillo -alcaldes del gremio de los sastres- recibieron dos solares para que levantaran un templo en honor a San Cosme, San Damián y San Amaro, a fin de que en ellos erigieran igualmente "un hospital a su costa donde se alberguen pobres y miserables personas que tuviesen necesidad, y para de donde saliesen sus oficios el día de Corpus Christi". ${ }^{52}$ Evidentemente se estaba haciendo alusión a la naturaleza jurídica de las miserabiles personae, buscando así que los ocupantes del hospital quedaran sujetos a estatutos proteccionistas específicos, jurisdicciones eclesiásticas particulares y mitigaciones en causas procesales. ${ }^{53}$ De manera adicional, cabe destacar que se trataba de un establecimiento dirigido a indígenas indefensos, menesterosos y enfermos sin aparente distinción étnica. Así, de acuerdo con las interacciones hispano-nahuas que venimos señalando y que se hacen evidentes en este espacio, en los primeros años de la post-conquista el concepto de "miserable" no se aplicó de forma exclusiva a la población indígena, como sucedió posteriormente. ${ }^{54}$ Hacia 1536, no obstante, se habría empezado ya a vehicular su recalificación jurídica protectora y privativa para con los nativos. Y es que, en el juicio de residencia

529 de enero de 1526, libro 1, ACCM, p. 71.

${ }^{53}$ Carlos Sempat Assadourian, "Fray Bartolomé de Las Casas obispo. La naturaleza miserable de las naciones indianas y el derecho de la Iglesia. Un escrito de 1545": Historia Mexicana, 40: 3 (1991), pp. 387-451.

${ }^{54} \mathrm{Al}$ respecto, véase una discusión crítica en torno a la evolución de la miserabilidad jurídica en la América virreinal en Caroline Cunill, "La protectoría de indios en América. Avances y perspectivas entre historia e historiografía": Colonial Latin American Review, 28: 4 (2019), pp. 478-495. Caroline Cunill, "L'accompagnement juridique aux Indiens en Nouvelle Espagne. Regards croisés entre l'Audience de Mexico et le tribunal du gouverneur du Yucatan": Bernard Grunberg (dir.), Les fêtes en Amérique coloniale. Cahiers d'Histoire de l'Amérique Coloniale, 8 (2020), pp. 157-173. 
efectuado a las autoridades de la Segunda Audiencia, se aseveró que "[...] miserables personas como los dichos naturales lo son".55

Aunque del hospital no logramos encontrar mayores datos, sabemos que, en la década de 1540, con la institucionalización del diocesano Hospital del Amor de Dios, también llamado el de las Bubas, la cofradía de sastres, dedicada a San Cosme y San Damián, quedó adscrita a éste. 56 De hecho, por su filiación al clero diocesano, tal y como señalamos en la figura 2, ni siquiera aparece glosada en el Mapa de Uppsala, en franco contraste con los sitios vinculados a los franciscanos, que se destacan y se les nombra.

\section{Las Casas de Tapia}

Un tercer espacio al suroriente de la Iglesia Mayor fue el de las Casas de Tapia. Se trata de uno de los domicilios del citado quauhtlahtoani tenochca Motelchiuhtzin, construido por mandato suyo en torno a 1526, y en el que vivió igualmente su hijo Hernando de Tapia tras su regreso de España hacia 1537, cuando se convirtió, por esas fechas, en nahuatlato de la Real Audiencia de México. Dicho espacio -localizado en el vecindario o tlaxilacalli de Tozanitlan- fungió igualmente como sede de la gobernación indígena de México-Tenochtitlan durante las décadas siguientes a la conquista. De hecho, encontramos representado este inmueble en el Mapa de Uppsala, donde aparece con una veleta a manera de ave negra, posiblemente un gallo, símbolo español. En su friso, figuran unos chalchihuites; es decir, un símbolo iconográfico de autoridad alusivo a las casas del gobierno indígena. ${ }^{57}$

En efecto, Tapia, a raíz de su estancia en Castilla durante el período 1532-1537, contrajo matrimonio con la hidalga doña Isabel de Cáceres. Este tipo inusual de enlaces interétnicos -en los que el conyugue fue un hombre indígena "principal"- incumbió al estrato elitista nahua más

${ }^{55}$ Escobar Olmedo, Don Vasco, p. 250.

${ }^{56}$ Cfr. Melchor Hurtado, "Concierto de servicios", 13 de marzo de 1579, ciudad de México: Catálogo de Protocolos del Archivo General de Notarías de la Ciudad de México, Fondo Siglo XVI: Ivonne Mijares (coord.). Seminario de Documentación e Historia Novohispana, México, UNAM-Instituto de Investigaciones Históricas, 2014.

${ }^{57}$ León-Portilla y Aguilera, Mapa de México Tenochtitlan. 
privilegiado que viajó tempranamente a la Corte de los Habsburgo. ${ }^{58} \mathrm{El}$ matrimonio tuvo dos hijas, Inés y Sebastiana de Tapia.

Merced a las informaciones que nos interesan, el testamento de Hernando de Tapia -fechado el 26 de marzo de 1555- nos arroja datos altamente significativos. Sabemos que el testador expresó que

"mando que mi cuerpo sea enterrado en la iglesia de San Pablo donde yo tengo mi entierro para mí y para mis sucesores [...] ítem: mando que me entierren dos curas y un sacristán, y se les pague por ello de mis bienes lo que es costumbre". 59

La última voluntad de Tapia se centró también en otorgar limosnas y solicitar diez misas rezadas al ya aludido Hospital de las Bubas, en dejar asignadas donaciones al Hospital de Ntra. Señora de la Concepción, en dejar señalado que se pagaran al canónigo Rodrigo de Ávila cincuenta pesos de tepuzque por una taza y un jarro de plata, en manifestar que sus dos hijas se casaran con españoles, y en dejar constancia de que había sido integrante de las cofradías urbanas de la Santa Veracruz y Santa Catalina -ambas de origen español-, entre otras cuestiones. ${ }^{60}$

La relación de Tapia con el clero secular se hace aún más evidente a partir de un pleito ante la Real Audiencia por la titularidad de este inmueble, que enfrentó a sus herederos con las autoridades del cabildo indígena de San Juan Tenochtitlan en 1576. Tras un primer fallo favorable a los intereses de la familia, se estuvo en condiciones de acreditar que, de forma adicional, en las Casas de Tapia,

"si algunas personas, así clérigos como legos, posaron [por] algún tiempo [...] fue por el beneplácito del dicho Hernando de Tapia, su padre y herederos, y con su consentimiento porque, como dueños propietarios de las dichas casas y gente caritativa y honrada, acomodaban y daban posada a los que no tenían donde posar."61

58 Pedro Carrasco, "Indian-Spanish Marriages in the First Century of the Colony": Susan Schroeder et al. (eds.), Indian Women of Early Mexico, Norman / Londres: University of Oklahoma Press, 1997, pp. 90-92.

59 "Testamento de Hernando de Tapia", 26 de marzo de 1555, ciudad de México. Folios 77v-94v: folio 80v. AGN, Tierras, vol. 37, exp. 2.

60 "Testamento de Hernando de Tapia”, folios 81r, 85v, 89v, 91r.

${ }^{61}$ Toribio González, procurador de la mujer y herederos de Hernando de Tapia, "Respuesta de absolución a la sentencia, con quita y libertad de costas", 1 de octubre de 1577, ciudad de México. Folios 61r-61v: folio 61r. AGN, Tierras, vol. 37, exp. 2. 
El asunto de los clérigos no fue baladí, pues cabe recordar que, un año antes de la querella, en 1575, San Pablo había sido transferida a la Orden de San Agustín tras un periodo en el que la colación estuvo formalmente secularizada (ca.1555/1562-1575). Así, en un interrogatorio incorporado a la pieza judicial, se trasladaron no únicamente dudas sobre la presencia del clero secular, sino igualmente incertidumbres acerca de los ingresos que ello habría ocasionado. ${ }^{62}$ Como respuesta a estas interrogantes, un testigo afirmó que

"a la octava pregunta de ello, que este testigo vio posar en las dichas casas [de Tapia] a los clérigos que daban misa en la iglesia de San Pablo y el testigo oyó decir que los dichos clérigos no pagaban nada por posar en las dichas casas."63

En suma, Hernando de Tapia y su ámbito doméstico estuvieron en contacto con el mundo español, evidenciando, de ese modo, su propensión por buscar apoyo en el clero secular y por intentar crear una clientela espiritual interétnica. Sin embargo, la siguiente generación truncó tal dinámica al fomentar aún más una profunda hispanización, puesto que su viuda, Isabel de Cáceres, contrajo segundas nupcias con el español y minero Luis de Zamora. ${ }^{64}$

\section{San Pablo}

En esta topografía que estamos examinando, cabría incluir la ermita y colación de San Pablo. Aunque su fundación se retrotrae a los primeros tiempos del apostolado misionero franciscano, ocupando el espacio en el que se había erigido el templo prehispánico de Huitznáhuac, ${ }^{65}$ el promotor de las obras fue el ya referido Motelchiuhtzin, cuando estuvo

\footnotetext{
62 "Los herederos de Hernando de Tapia // Ha se de cometer // Por las preguntas siguientes sean preguntados y examinados los testigos que son y fueren presentados por parte del gobernador, alcaldes, regidores y principales de la parte de México [...]", 6 de noviembre de 1577, ciudad de México. Folios 99r-100r: folio 99v. AGN, Tierras, vol. 37, exp. 2.

63 "Testimonio de Agustín Quauhtli, natural de Iztapalapa". Folios 102v-104r: 103v. AGN, Tierras, vol. 37, exp. 2.

${ }^{64}$ Rossend Rovira Morgado, San Francisco Padremeh. El temprano cabildo indio y las cuatro parcialidades de México-Tenochtitlan (1549-1599), Madrid: Consejo Superior de Investigaciones Científicas, 2017, p. 158.

${ }^{65}$ Hernando de Alvarado Tezozómoc, Crónica mexicana, Madrid: Dastin, 2001 [ca. 1598], cap. LXXI, p. 304.
} 
ejerciendo la gobernación indígena en la ciudad (1526-1529).66 Según hemos visto ya, no parece aventurado sostener que Motelchiuhtzin y su parentela diesen hospedaje ocasional a los primeros clérigos y curas que, como el citado capellán Alejo de Villanueva, empezaron a circular también por la capital y a estar a cargo de los primeros intentos institucionales de consolidar una parroquia en San Pablo a inicios de los años de 1530. Ese vínculo religioso se afianzaría con mayor firmeza en la siguiente generación, con Hernando de Tapia, con el establecimiento a perpetuidad del panteón familiar y con la institucionalización de un beneficio presbiteral en forma de capellanía.

Acotando un poco más la cronología, podemos plantear que las obras de la prístina ermita indígena de San Pablo se iniciarían en 1528-1529.67 El santo patrón de ese distrito sureste de la ciudad era dual -San Pedro y San Pablo-. ${ }^{68}$ Así quedó asentado en la misiva real girada a Juan Fernández, embajador español en la Santa Sede:

En la dicha ciudad de México hay dos iglesias que se dicen la una San Pedro y San Pablo y la otra, Santiago. Procuraréis que se les conceda una indulgencia para los días de su advocación $[\ldots] .{ }^{69}$

No deja de ser sugestivo relacionar la mención en torno a las iglesias de San Pablo y Santiago -así como los jubileos papales solicitados en 1538tanto con la ya citada promoción a sedes parroquiales que se había ensayado en ellas ocho años antes como con el hecho de que ambos lugares fueran las cabeceras de las dos gobernaciones indígenas en la

${ }^{66}$ AGI, México, leg. 2637. Matthew D. O’Hara, A Flock Divided. Race, Religion, and Politics in Mexico, 1749-1857, Durham: Duke University Press, 2010, pp. 108109, 258. APSPA, Sección Disciplinar, Serie Comunicaciones, caja 190, "Testimonio íntegro de lo ocurrido en la secularización del curato de San Pablo". Candy Elizabeth Ornelas Méndez, Inventario del Archivo de la Parroquia San Pablo Apóstol, Arquidiócesis de México, Ciudad de México, México: Apoyo al Desarrollo de Archivos y Bibliotecas de México, A.C., 2015, pp. 10-11.

${ }^{67}$ En 1528 aún no aparece en las fiestas de la ciudad. 31 de julio de 1528, libro 1, ACCM, p. 176.

${ }^{68}$ Obadia-Baudesson, Historia de los mexicanos, cap. XIX, p. 77.

${ }^{69}$ Instrucciones de Carlos V, "Al embajador que está en Roma [...]”, 18 de marzo de 1538, Valladolid. Folios 17v-19r: folios 18v-19r. AGI, México, 1088, L.3. 
capital. ${ }^{70}$ Y es que, más allá de entender que esos dos templos cristianos se ubicaban igualmente en los límites meridional y septentrional de la urbe -evidenciando, así, la voluntad de articular un espacio preferente de feligresías sujetas a clérigos seculares en la franja centro-oriental y este de la capital-71, resulta igualmente oportuno recordar que estos ámbitos urbanos indígenas habían mantenido estrechas relaciones administrativo-tributarias antes de $1521 .{ }^{72}$ Tales nexos parecen haberse prolongado a lo largo del siglo XVI, pues descendientes de los gobernadores militares prehispánicos en Tlatelolco vivían y poseían inmuebles en esa zona sureste. ${ }^{73}$ Asimismo, tenemos noticia de que, en la década de 1560, los "señores de Tlatelolco" iban a escuchar misa a San Pablo. ${ }^{74}$ Así pues, todo ello invita a considerar los vínculos entre ambas parroquias y la posibilidad que, de manera conjunta, se planteara en ellas la actividad del clero secular.

Por consiguiente, podemos sostener que, entre 1529 y hasta poco después de 1555-1556 -sin reparo tampoco con la presencia de iure del clero secular-, las autoridades regulares persiguieron que San Pablo se practicase de facto como una "ayuda" franciscana de la doctrina de San José de los Naturales. Esto implicaba que los indígenas únicamente debían acudir, en gran algarabía, a la ermita con motivo de la celebración de los oficios durante la fiesta patronal de la colación $(29$ de junio); en los domingos y otros días de guardar, su feligresía tenía que concentrarse en el atrio del inmueble para ser conducida a la capilla doctrinera de San José; y a diario, los principales grupos de la elite entre los naturales debían encargarse del cuidado externo, del acicalamiento

${ }^{70}$ Reiteramos que no fue sino hasta 1543 que se fijaron un convento seráfico, una guardianía y una cabecera de doctrina regular autónomos en Tlatelolco. Robert $\mathrm{H}$. Barlow, Tlatelolco. Fuentes e historia, México: INAH, 1989, p. 373.

${ }^{71}$ Ramírez Méndez, "Las nuevas".

72 Tlatelolco aportó tandas rotatorias de trabajadores para realizar reparaciones periódicas en el aludido templo tenochca de Huitznáhuac, antecedente de la iglesia de San Pablo. Códice mendocino, ca. 1542, folio 19r. Pedro Carrasco, Estructura político-territorial del Imperio tenochca. La Triple Alianza de Tenochtitlan, Tetzcoco y Tlacopan, México: COLMEX-FCE, 1996, pp. 146,169.

${ }^{73}$ AGN, Tierras, vol. 32, exp. 1. Luis Reyes García et al. (eds.), Documentos nauas de la Ciudad de México del siglo XVI, México: CIESAS-AGN, 1996, pp. 136-138.

${ }^{74}$ Luis Reyes García (ed.), ¿Cómo te confundes? ¿Acaso no somos conquistados? Anales de Juan Bautista, México: Biblioteca de la Insigne y Nacional Biblioteca de Guadalupe-CIESAS, 2001 (1582), pp. 299-301. 
y de la vigilancia de la propia ermita. ${ }^{75}$ Pero, de nuevo, en un espacio aún no territorializado, lo que prevaleció en torno a las relaciones de los catecúmenos con la Iglesia fueron sus vínculos personales con algún miembro de uno y otro clero para que velara por el cuidado de su alma.

En la segunda mitad de la década de 1550, la situación comenzó a cambiar. El beneficio económico de los Tapia en San Pablo se apuntaló en favor de los clérigos, quienes empezaron a frecuentar con más asiduidad la colación junto a los provisores de indios, ${ }^{76}$ a lo cual los franciscanos se opusieron a partir de los años de 1560. ${ }^{77}$

\section{Santa Clara: beaterio, casa y monasterio}

En agosto de 1529, Isabel de Portugal encargó a Zumárraga que se ocupara de la "casa de las dichas religiosas de naturales e hijas de españoles" que los franciscanos le habían pedido se fundara en la ciudad de México. ${ }^{78}$ Para ello mandó se erigiera una "casa y monasterio" en el lugar que pareciera conveniente a los frailes seráficos junto con el obispo electo, para lo que, aparte de los gastos del viaje de las beatas, ${ }^{79}$ aportó 200 pesos de oro de su hacienda, ${ }^{80}$ y lo restante, al parecer salió

\footnotetext{
${ }^{75}$ Véase en Jerónimo de Mendieta, Historia eclesiástica indiana, México: Antigua Librería, 1870 (1596), Libro IV, cap. XXXII, pp. 496-501.

${ }^{76}$ Véase Códice Osuna, ca. 1565, folio 8v.

${ }^{77}$ Rossend Rovira Morgado, “'El altepetl ya se quiere dividir'. Espacios doctrinales indígenas y frailes franciscanos en la Ciudad de México frente al reto de la secularización diocesana, siglo XVI": James Amelang et al. (eds.), Palacios, plazas, patíbulos. La sociedad española moderna entre el cambio y las resistencias, València: Tirant Lo Blanch, 2018, pp. 747-758.

78 "La Reina al consejo, justicias, regidores, caballeros, oficiales y hombres buenos de la ciudad de Tenochtitlan", 10 de agosto de 1529, Toledo y "La Reina al obispo fray Juan de Zumárraga”, 24 de agosto de 1529, Toledo. Folio 38r y Folios 55v-56v respectivamente. AGI, México, 1088, L. 1.

79 “La Reina al doctor Beltrán del Consejo de Indias” y “La Reina a fray Antonio de la Cruz", ambas del 14 de enero de 1530, Madrid. Folios 148v-149r y folio 150r respectivamente. AGI, México, 1088, L. 1.

80 "Cédula de la Reina a la Audiencia", 4 de febrero de 1530, Madrid: Francisco González de Cosío (ed.), Un cedulario mexicano del siglo XVI, México: Ediciones del frente de afirmación hispanista, A.C., 1973, p. 21.
} 
de los diezmos. ${ }^{81}$ Además, aunque la puso al cuidado del obispo, no la sujetó a ninguna "de las religiones". 82

En diciembre de 1530 llegaron seis beatas. ${ }^{83}$ Con el dinero aportado por la Corona, Zumárraga compró dos viviendas de vecinos para construir la casa y monasterio; es decir, la habitación de las beatas y el sitio para instrucción de las niñas. ${ }^{84}$ El beaterio se estableció detrás de las Casas Nuevas que, ${ }^{85}$ más allá de su probable connotación simbólica heredada del mundo prehispánico, ${ }^{86} \mathrm{y}$ de la instrucción de la emperatriz de asentar la casa de mujeres cerca de la Iglesia Mayor, destaca la elección del obispo por instaurarlo en la territorialidad que comenzaba a configurar en torno a la calle de Martín López.

Igualmente es notorio que, aunque la reina había instruido que el beaterio fuera para indias y españolas, el electo dirigió la casa de

81 "Carta de la Abdyencia”, p. 119.

${ }^{82}$ Real cédula de Isabel de Portugal con instrucciones a la Audiencia de México, "Casas de beatas se funden", 12 de julio de 1530, Madrid. Puga, Prouisiones, folio 42r [año MDXXXI].

${ }^{83}$ Mientras se adecuaba el espacio en el que morarían, las beatas se establecieron en casa de la viuda de Alonso de Estrada, Marina Gutiérrez Flores de la Caballería, que vivía frente a la plaza del Volador (esquina de Pino Suárez con Carranza). "Carta de la Abdyencia", p. 114.

84 "Carta de la Abdyencia”, pp. 118-121 y "Al presiente e oidores de la Audiencia Real de la Nueva España; que provean que una casa que hay en México en que solían doctrinar las hijas de los caciques, se de al hospital de bubas", 8 de noviembre de 1546, Madrid: Genaro García (ed.), Documentos inéditos o muy raros para la historia de México. El clero de México durante la dominación española según el archivo inédito archiepiscopal metropolitano, tomo XV, México: Librería de la viuda de Ch. Bouret, 1907, p. 103.

85 "Arrendamiento", 29 de diciembre de 1557, Catálogo de Protocolos del Archivo General de Notarías de la Ciudad de México, fondo Siglo XVI: Ivonne Mijares (coord.), Seminario de Documentación e Historia Novohispana, Ciudad de México: Instituto de Investigaciones Históricas-UNAM, 2014.

${ }^{86}$ Esa zona había pertenecido al bestiario de las Casas Nuevas de Motecuhzoma Xocoyotzin, el cual tuvo funciones asistenciales en uno de sus segmentos; a su vez, colindaba con lo que había sido el Tlillancalco, espacio de feminidad. Israel Elizalde Méndez, "Los animales del rey. El vivario en el corazón de Tenochtitlan": Arqueología Mexicana, 25: 150 (2018), pp. 77-83. Stan Declercq, "Tlillan o el 'lugar de la negrura'. Un espacio sagrado del paisaje ritual mesoamericano": Estudios de Cultura Náhuatl, 15 (2016), pp. 67-110. "Descubren estructuras prehispánicas": Boletines de prensa-INAH, 1844 (6 de juni de 2008). 
mujeres para la nobleza indígena, como lo habían venido haciendo los franciscanos en otros establecimientos. ${ }^{87}$ Más allá de la cercanía con sus hermanos de orden, probablemente Zumárraga pretendía evidenciar con ello su función como protector de indios. ${ }^{88}$ De hecho, la Segunda Audiencia llamó la atención sobre el interés que se estaba poniendo en la casa de mujeres, afirmando que "cosa nueva en estas partes [es] facer tanto caso de yndios, especialmente faciendo edyficios de gobernación, $[\ldots] " .89$

La fundación albergó a mujeres indígenas nobles para ser evangelizadas e instruidas por las beatas, ${ }^{90}$ a la vez que aprendían y realizaban trabajo manual que ayudara en su manutención. Esta idea se aproximaba a lo que, desde 1525, había propuesto Rodrigo de Albornoz. ${ }^{91}$ Empataba también con los ichpochcalli, que habían sido los

${ }^{87}$ Los franciscanos habían fundado previamente establecimientos de educación femenina en Huejotzingo y Texcoco. Este último terminó por diluirse ante las confrontaciones entre Cortés-franciscanos y la Primera Audiencia. Luego también se involucró Zumárraga en su calidad de protector de indios y, seguramente, en defensa de sus hermanos de orden. "Acusación presentada por Fray Juan de Zumárraga protector de los indios, y otros graves religiosos contra el oidor Don Diego Delgadillo", 19 de octubre de 1529, Texcoco: Mariano Cuevas, Historia de la Iglesia en México, vol. I, apéndices, México: Imprenta del asilo Patricio Sanz, 1921, pp. 457-458.

${ }_{88}$ Cabe remarcar que, aunque en la etapa pre-diocesana (1524-1528) primero franciscanos y, luego, añadiéndose los dominicos, se atribuyeron la protectoría de indios, ésta terminó convirtiéndose en un oficio del obispo Juan de Zumárraga entre 1528 y 1534. En este último año la protectoría se traspasó a la Real Audiencia de México, deslizándose, de ese modo, hacia la esfera de gestión civil y seglar. Cunill, "La protectoría".

89 "Carta de la Abdyencia”, p. 118.

90 "Provisión de las primeras maestras que vinieron de España a México para la enseñanza de las niñas indígenas, 1530”, 14 de febrero de 1530, Madrid: Lino Gómez Canedo, La educación de los marginados durante la época colonial. Escuelas y colegios para indios y mestizos en la Nueva España, México: Porrúa, 1982, p. 308.

${ }^{91}$ El contador había sugerido establecer un beguinaje a la manera de Flandes; esto era, un sitio autosuficiente que albergaba mujeres dedicadas a la vida religiosa, no conventual, y que, en este caso, su principal función sería la cristianización de la élite femenina indígena. "Carta del contador Rodrigo de Albornoz al Emperador", 15 de diciembre de 1525, Temistitlán México: Joaquín García Icazbalceta (ed.), 
centros prehispánicos de educación de niñas y jóvenes donde vivían hasta que se casaban "a manera de recogimiento, que querían parecer monjas", en castidad y elaborando trabajos como el tejido de pluma. ${ }^{92}$

Para 1531 ya estaba funcionando la casa atendida por mujeres seglares, constituida como una comunidad independiente de toda jurisdicción eclesiástica, ${ }^{93}$ aunque bajo el cuidado del clero secular. Al respecto, muy pronto se presentaron diversos problemas. El primer conflicto se dio en ese mismo año, dada la relación espiritual de una de las beatas, Catalina Hernández, con Calixto de Sa. Aunque no lo desarrollaremos, detrás del conflicto estaba la intervención de Zumárraga en la vida de las beatas $\mathrm{y}$, desde su perspectiva, el inconveniente de que fueran frecuentadas por seglares; asimismo, se hizo patente la crítica que hizo la beata al poder de los franciscanos entre los que se incluyó a Zumárraga- que, según Catalina Hernández, controlaban a los miembros de la Audiencia. ${ }^{94}$

Por su parte, el electo insistía en poner a las beatas bajo clausura, pero la respuesta de la Corona ante las demandas episcopales aún en 1534 siguió siendo que las beatas no fueran visitadas por los franciscanos ni las pusieran bajo regla alguna, proveyendo que fueran visitadas por la autoridad seglar de los oficiales de la Audiencia. ${ }^{95} \mathrm{De}$ hecho, aunque en septiembre de 1536 la reina escribió al diocesano agradecida en torno al trabajo que se estaba haciendo con las "hijas de caciques y principales" y por el crecimiento que estaban teniendo las casas, ${ }^{96}$ el obispo insistió en que debían quedar sujetas a su autoridad. Alegaba que, ante la libertad de la que gozaban, los indios principales

Colección de documentos para la historia de México, vol. 1, México: Librería de J. M. Andrade, 1858, pp. 484-511.

92 Este espacio había estado situado cerca "del gran cu de Uichilobos"; es decir, en torno a la zona donde quedó establecido el beaterio. Bernal Díaz del Castillo, Historia verdadera de la conquista de la Nueva España, México: Editorial Pedro Robredo, 1939, tomo I, cap. XCI, p. 326

93 "Carta al Capítulo General de Tolosa, celebrado en 1531", 12 de junio de 1531, México: García, Don Fray, tomo II, p. 308.

94 "Carta de la Abdyencia”, pp. 115-118.

95 La Reina a la Real Audiencia, "Que provea que los franciscanos no visiten ya a unas beatas de México", 27 de noviembre de 1534, Madrid: García, Documentos inéditos, pp. 33-34.

96 "La Reina a fray Juan de Zumárraga", 3 de septiembre de 1536, Valladolid: González Cosío, Un cedulario, p. 42. 
no querían entonces enviar a sus hijas, pues ellos solían educarlas en las citadas casas de clausura. ${ }^{97}$ Las beatas se defendían recordando que no eran monjas y hasta solicitaron autorización para pedir limosna, pues, decían, no eran esclavas y necesitaban recursos para médico y botica. ${ }^{98}$

Ante ello, en noviembre de ese año de 1536, Zumárraga escribió al Consejo de Indias para que las casas para las hijas de caciques y de gentes principales fueran dirigidas por monjas, pues "de las mujeres seglares no vemos la doctrina y fructo que los religiosos han plantado".99 Ahí se educarían desde los cinco años hasta ser desposadas. ${ }^{100}$

En franco alejamiento del proyecto de gobierno que involucraba a la nobleza indígena, un año después el obispo solicitó que hubiera casas para que fueran enseñadas y doctrinadas de manera general "las niñas hijas de los naturales" y "en sitio que esté entre los mismos indios, no entre los españoles". Para ello pidió la ayuda de la Corona, pues no podía sustentar ni a las niñas ni a las personas que las enseñaban por lo que andaban fuera al no tener con qué darles de comer, vestir y calzar y pagar médicos y medicinas: "no se ha hecho cosa alguna mas de lo q yo hize antes q de aquí me fuese a su corte [...] no les he podido ayudar como qria y tengo el deseo pa q tan santa y bendita obra como se haze vaya adelante". ${ }^{101}$ Así, más allá de la desobediencia de las beatas y de la escasez económica, alegaba el obispo que había desatención por parte de los agentes seglares. Esto probablemente se debía a que el proyecto de organización que vinculaba a españoles y a personalidades indígenas iba en declive para cuando el obispo regresó a Nueva España en 1534.

97 "Carta de don fray Juan de Zumárraga al Emperador", 25 de noviembre de 1536, México: Mariano Cuevas (ed.), Documentos inéditos del siglo XVI para la historia de México, México: Porrúa, 1975, p. 61.

${ }^{98}$ La Reina a la Real Audiencia, "Que se provea si conviene permitir que unas beatas pidan limosna", y "Que se provea si la Real Hacienda debe pagar a un físico y un boticario que cuiden de unas beatas", 27 de noviembre de 1532, Madrid: García, Documentos inéditos, pp. 18-20.

99 "Carta de don fray Juan de Zumárraga al Consejo de Indias", 24 de noviembre de 1536, México: Cuevas, Documentos inéditos, p. 57.

100 "Carta de don fray Juan de Zumárraga al Emperador", 25 de noviembre de 1536, México: Cuevas, Documentos inéditos, p. 61.

101 "Carta de los obispos de México y Oaxaca a su Majestad", 22 de septiembre de 1537: Frances V. Scholes (ed.), "Unpublished letters of the First Bishop of Mexico and Oaxaca, 1537": The Americas, 1:1 (1944), pp. 105-106. 
No obstante, reiterando su petición anterior, Zumárraga -ahora junto con los obispos de Oaxaca y Guatemala- escribió al emperador para el establecimiento de un monasterio de monjas profesas donde se adoctrinara y educara a niñas indias y que permanecieran encerradas hasta casarse, pues, al no estarlo, "las dan de mala gana, porque en su gentilidad las solían tener muy encerradas y como nadie las viese". A su vez desacreditaba a las beatas porque "andan fuera y disponen de si a su voluntad". Además, afirmó que muchas se habían ido.102 Veinte días después reiteró su propuesta, dejando claro que la casa debía estar bajo la obediencia del prelado. ${ }^{103}$ Pero la Corona se negaba a vincularlas a alguna autoridad eclesiástica pues no quería monjas, por lo que, en 1538, estaba aún promoviendo el mismo funcionamiento de la casa y su reparación. ${ }^{104}$

Igualmente, ante la solicitud que en 1538 hizo el cabildo de la ciudad para fundar una casa de mancebía, la universidad y dos conventos de clausura, uno de dominicas y otro de franciscanas, la Corona aceptó los dos primeros. Pero lo último lo rechazó, igual que como lo había hecho con la propuesta de los obispos, pues "por agora no debe haber en las indias monasterios de monjas". ${ }^{105}$ Aunque el diocesano estaba pidiendo un monasterio para indígenas bajo su jurisdicción y el cabildo de la ciudad lo hacía para españolas cobijadas por el clero regular, ninguno fue aceptado.

102 "Carta de los Ilustrisimos, Señores Obispos de México, Oaxaca y Guatemala sobre la ida al Concilio General, y piden sobre distintos puntos, así de Diezmos, como otros para la buena planta y permanencia de la fe de este Nuevo Mundo", 30 de noviembre de 1537, México: García, Don Fray, tomo III, pp. 94-124.

103 "Carta del obispo de México, Fray Juan de Zumárraga á Juan de Samano, secretario de S. M., haciéndole presente algunas necesidades de sus diocesanos y rogándole que apoyara su proyecto de edificación de colegios y monasterios para jóvenes de ambos sexos", 20 de diciembre de 1537, México: Ministerio de Fomento (ed.), Cartas de Indias, Madrid: Imprenta de Manuel Hernández, 1877, p. $169-170$.

104 "El rey al virrey de la Nueva España, que vea el edificio questá hecho en el colegio que tienen los hijos de los naturales de aquella tierra, y considerada la utilidad que dello podrá resultar, provea cómo se haga el dicho colegio de manera que tenga perpetuidad", 3 de agosto de 1538, Valladolid: Carreño, Un desconocido, p. 126.

105 "El rey. Respuesta a los obispos de México y Guaxaca y Guatimala (sobre diversos puntos)”, 23 de agosto de 1538, Valladolid: Carreño, Un desconocido, p. 120. 
Ante la negativa de la fundación y el debilitamiento del proyecto interétnico, en 1540 el obispo se alejó del impulso de educar a la población tenochca. Para principios de los años cuarenta, el beaterio funcionaba como una comunidad mixta que tenía monasterio, beaterio, colegio y hospital de vírgenes pobres, y seguía sin estar sujeta a ninguna autoridad eclesiástica. ${ }^{106}$

En 1544 Zumárraga explicó el cese de la casa de las niñas debido a que los indios no querían casarse con ellas, "diciendo que se criaban ociosas y a los maridos los ternían en poco, ni los querían servir según la costumbre suya que ellas mantienen a ellos". Así daba por terminado ese proyecto, anunciando "se han ido casi todas a casa de sus padres e ya no hay en la casa más de cuatro o cinco indias mayores" y una de las que envío la reina, "Ana de Mesto, se va a Sevilla para no volver acá, en esta flota; y así queda la casa despoblada." ${ }^{107}$ En contraposición, fundó el ya comentado Hospital de Bubas, que era para españoles. ${ }^{108}$ De hecho, decidió aportarle recursos que antes había destinado para los establecimientos dedicados a la instrucción de la nobleza indígena: el colegio de Santiago Tlatelolco y el de niñas.

En 1549 el canónigo Francisco Rodríguez Santos solicitó la "casa donde se solían doctrinar las hijas de los caciques" en favor del hospital del Amor de Dios, que le fue otorgada el 21 de agosto. ${ }^{109}$ Por su parte, el beaterio se fue reconfigurando, convirtiéndose para las naturales sólo

${ }^{106}$ Diana Barreto, La fundación del convento de Jesús María a partir del Convento de Nuestra Señora de la Inmaculada Concepción (el monasterio de la Madre de Dios), México: Posgrado en Historia-UNAM, 2012 (tesis de maestría en Historia), p. 7.

107 “Carta de don fray Juan de Zumárraga al príncipe don Felipe”, 2 de junio de 1544, México: Cuevas, Documentos inéditos, pp. 122-123.

${ }^{108}$ Esto se intuye a partir de la contraposición al señalar que "[...] muchos morían sin sacramentos como desesperados por los pueblos de los indios y caminos [...]". "Carta de Don fray Juan de Zumárraga al emperador", 17 de abril de 1540, México: García, Don Fray, tomo III, p. 204.

${ }^{109}$ Audiencia de México al alguacil mayor, "Mandamiento para que el alguacil desta corte, conforme a los autos desta Audiencia, meta a la parte del hospital de las bubas en la posesión de las casas", 21 de agosto de 1549, México: García, Don Fray, tomo IV, pp. 24-28. 
en "buen ejemplo"110, pues la comunidad de beatas empezó a recibir doncellas españolas que comenzaron a profesar como monjas. ${ }^{111}$

Aunque se diluyó la pretensión, los años treinta dejaron evidencias de esas tentativas corporativas donde participaban españoles e indígenas, como hemos ido viendo. Además, podemos añadir el papel protector de las beatas para con las indias retratado por el franciscano Motolinía. Si bien constituye parte del discurso de los mendicantes, nos interesa señalar que reportó que una india doncella molestada por dos mancebos fue acogida por esas "mujeres piadosas" y su comunidad; 112 lo que podría referir a un espacio de convivencia interétnica. Contamos también con el testimonio de Catalina López, en el proceso inquisitorial contra Martín Océlotl, acusado de idólatra y hechicero en 1536. Ella declaró que "lo que sabe del dicho Martín, indio, es que al tiempo que Don Pablo [Xochiquentzin], Gobernador que fue de México, estaba malo, este testigo y la beata de las niñas de Santa Isabel, iban algunas veces á le ver y á curar". Es más, en una de sus visitas a la residencia del gobernador -probablemente representada en el Mapa de Uppsala bajo la glosa "Casa de don Pablo"- los indios no la dejaron pasar, hecho que motivó su queja ante el alguacil del tianguis. ${ }^{113}$

A partir de esta testificación sabemos que las beatas ejercían tareas asistenciales con las "curas que le echaban, que eran medicinas de Castilla" al gobernador. La declaración trasluce, asimismo, la relación que existía entre las beatas y la gobernación indígena que en ese entonces desempeñaba Xochiquentzin, lo cual implica también una asociación entre los espacios que cada uno ocupaba al oriente de la ciudad. Igualmente cabe destacar la interpelación ante un interlocutor vinculado con el cabildo español -como lo era el alguacil del tianguispor la desavenencia de los oficiales indígenas contra Catalina López.

${ }^{110}$ Las monjas, "A Su Majestad de la abadesa y convento de México", 15 de febrero de 1552, México. Folio 1r/355r. AGI, México, 280, N. 61.

${ }^{111}$ Las primeras dos profesiones fueron en 1541, en el que tomaron el hábito Ana de Sotomayor y Margarita de Echánez, descendientes de conquistadores. Ramírez Méndez, “¿Ubicaciones fortuitas?”, pp. 49-78.

${ }^{112}$ Fray Toribio de Benavente, Historia de los indios de la Nueva España, Madrid: Real Academia Española, 2014, parte III, cap. XV, p. 244.

113 "Proceso del Santo Oficio contra Martín Ucelo, indio, por idólatra y hechicero", 21 de noviembre de 1536, México. AGN, Procesos de indios idólatras y hechiceros, tomo III, México: tip. Guerrero hermanos, 1912, p. 26. 
Sería interesante retomar aquí esa figura del alguacil del tianguis. Aunque este cargo español tenía atribuciones defensoras para con los indígenas, coincidía en algunas funciones con otro oficial, el procurador de pobres, bien estudiado en el caso particular de Vicencio de Riverol. Este se ocupó de velar también por los individuos que fueran españoles. ${ }^{114}$ De ese modo, en ciertas biografías quedarían claras las interacciones hispano-nahuas que venimos mostrando.

Por último, el testimonio hace evidente que la casa de mujeres indígenas se conocía como Santa Isabel, probablemente entre la propia comunidad de mujeres, ya sea en memoria de la reina y el apoyo que dio para la fundación o por las maestras que trajo Zumárraga del beaterio de Santa Isabel de Durango, Vizcaya, del que era protector. ${ }^{115}$ Distinto de ello, en el Mapa Uppsala consideramos que la etiqueta que aparece de "S. Clara" señala la casa de las beatas desde la mirada de los franciscanos, ${ }^{116}$ en defensa de su proyecto dado el propio discurso que revela la imagen, como ya hemos aludido. Esta forma de llamar ese lugar se contrapone a la que el arzobispo le dio en su testamento: "monasterio de las monjas de la Concepción de la Madre de Dios". ${ }^{117}$ Nombre que, por lo menos desde 1536, sabemos se utilizaba, pues aparece en un testamento en el que se le dejaron cuatro pesos de oro al "Monasterio

\footnotetext{
${ }^{114}$ Cunill, “L'accompagnement”. En la probanza de Juan de Riverol se expuso que su padre, Vicencio de Riverol, siendo procurador de [españoles] pobres en la Audiencia de México, igualmente "liberó muchos esclavos indios y asimismo tuvo en su casa enfermería y hospital de indios pobres y vio este testigo que de su pobreza les curaba y los que morían les hacía enterrar [...] y sirvió en los tianguis y mercados de esta ciudad por alguacil amparando a los naturales para que no se les hiciese agravio ninguno por ninguna persona". Probanza de Juan de Riverol, intérprete, 1565, México, AGI, México, 208, N. 32. Cunill, "L’accompagnement", p. 162.

${ }^{115}$ Richard E. Greenleaf (ed.), Zumárraga and His Family. Letters to Vizcaya 15361548, Washington, D.C.: Academy of American Franciscan History, 1979, p. XV.

116 Véase Jessica Ramírez Méndez, "La trama seglar en torno a una fundación conventual. El monasterio de Santa Clara de la Ciudad de México, 1566-1580": Roberto Di Stefano / Aliocha Maldavsky (comps.), Invertir en lo sagrado. Salvación y dominación territorial en América y Europa (siglos XVI-XX), Buenos Aires: Universidad de la Pampa, 2018, pp. 115-136.

117 "Memoria testamentaria del Sr. Zumárraga” y “Testamento del Sr. Zumárraga”, 2 de junio de 1548, México: García, Don Fray, tomo III, pp. 279-294.
} 
de la Madre de Dios". ${ }^{118}$ Como se percibe, cada nombre llevaba consigo una forma de concebir el espacio y su tutelaje. De hecho, conforme se fue definiendo como un espacio bajo la jurisdicción episcopal, las propias monjas lo nombraron "casa y monasterio de la madre de dios". ${ }^{119}$ Y, para cuando se consolidó como tal, se llamó de manera definitiva monasterio de La Concepción.

\section{Conclusiones}

Apenas transcurridos algunos años de la caída de México-Tenochtitlan, se planteó un temprano proyecto de agencia colectiva entre indígenas y españoles. A lo largo de este estudio hemos podido comprobar que hubo intentos por articular un gobierno con participación hispana e india, que logró involucrar temporalmente a individuos, corporaciones y espacios en la zona suroriental de la ciudad. Esta situación se aleja de la idea dicotómica tanto de las repúblicas -para dar cabida a líneas entretejidas entre ambos grupos étnicos- como de los cleros, en el que ambos lograron configurar feligresías basadas en vínculos personales, que no territoriales, por lo que interactuaban en espacios comunes. Igualmente este estudio trasluce la ciudad de esos años como una entidad heterogénea, con tramas y grupos de poder diversos.

A partir del estudio del área de las casas del obispo, la ermita de los sastres, las Casas de Tapia, San Pablo y el beaterio, pusimos de manifiesto otros andamiajes existentes entre actores que han sido poco estudiados. Eso se ha debido, en gran medida, por retrotraer los procesos de la segunda mitad del siglo XVI a la primera, por homogeneizar nuestra perspectiva de la reconstrucción de la ciudad, así como por seguir repitiendo el discurso de la época dorada construida por los mendicantes evangelizadores y que desdibujó en gran medida la presencia del clero secular. Queda claro que hubo otros ensayos de gobierno temporal y espiritual en estos años veinte y treinta.

Nos detuvimos en torno a inicios de la década de los cuarenta, pues es ahí donde se hace evidente un punto de inflexión en los años inmediatos al recibimiento de las Leyes Nuevas. Ante un fracaso inicial

118 "Testamento de Miguel García”, 9 de noviembre de 1536: Agustín Millares / José Ignacio Mantecón, Índice y extractos de los Protocolos del Archivo de Notarías de México, D.F., tomo I, México: El Colegio de México, 1945, doc. 2036, p. 72.

${ }^{119}$ Las monjas, "A Su Majestad de la abadesa y convento de México". 
del proyecto interétnico, la reinstalación de la dinastía legítima de Tenochtitlan, ostentando los primeros oficios de república en un cabildo indígena propio, bajo la gobernación del pro-franciscano don Diego Huanitzin (ca. 1538-1541), ${ }^{120}$ y elementos más locales relacionados con las amenazas de un levantamiento de naturales y negros en la ciudad, las autoridades españolas enfocaron entonces sus esfuerzos en arraigar a la población española. En esto cabe incluir la creación de parroquias que fueran proveídas "en los hijos de los vecinos" (1538), ${ }^{121}$ y a la fundación de espacios asistenciales dirigidos a los peninsulares y apoyados en algunas cofradías. ${ }^{122}$ Esto significaba una tendencia a agrupar ahora la población en corporaciones autónomas, reconfigurándolas hacia la identificación con territorios específicos. Tal es el caso que, en 1568, se definieron los distritos parroquiales (Santa Catarina, la Santa Veracruz y el Sagrario) que, como parte de la política de la secularización, terminarían por consolidarse a partir de la segunda mitad del siglo XVI.

120 María Castañeda de la Paz, Conflictos y alianzas en tiempos de cambio. Azcapotzalco, Tlacopan, Tenochtitlan y Tlatelolco (siglos XII-XVI), México: IIAUNAM, 2013, pp. 251-257. Mundy, The Death, pp. 95-105.

121 Real cédula de la Reina al virrey Antonio de Mendoza, [Para que se creen parroquias que puedan ser ocupadas por hijos de los vecinos de la ciudad], $16 \mathrm{de}$ abril de 1538, Valladolid. Folios 59r-59v. AGI, México, 1088, L. 3.

122 Josefina Muriel, La sociedad novohispana y sus colegios de niñas. Fundaciones del siglo XVI, México: IIH-UNAM, 2004, pp. 115-240. 